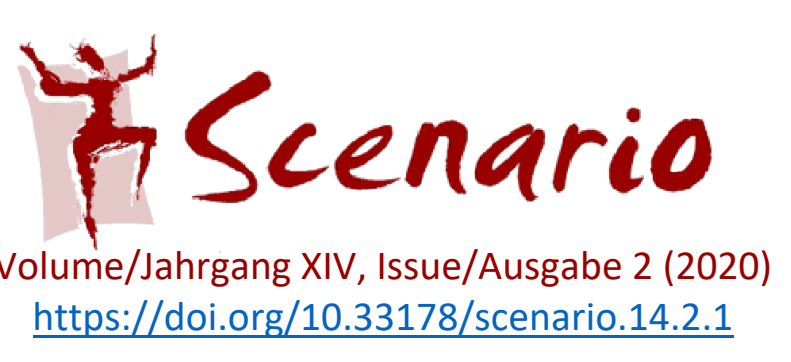

\title{
Teaching Through Performing Arts in Higher Education: Examples in Engineering and Psychology
}

Laure Kloetzer, Simon Henein, Ramiro Tau, Susanne Martin, Joëlle Valterio

This paper introduces two courses making use of performing arts at university level. The first course, taught by Prof. Simon Henein and his colleagues, called Improgineering, aims to teach collective creation through improvisation to master's degree students in engineering at the EPFL (Ecole Polytechnique Fédérale de Lausanne, Switzerland). The second course, taught by Prof. Laure Kloetzer and her colleagues, aims to introduce the Psychology of Migration via a sociocultural approach to bachelor's degree students in psychology and education at the University of Neuchâtel (Switzerland). After briefly introducing the topic of performing arts in higher education (section 1), the paper offers a description of the two courses (sections 2 and 3). These are complemented by teachers' and students' impressions of the course, as analyzed from individual interviews, focus groups and students' learning diary entries (section 4). The conclusion presents some reflections on the convergences of the pedagogical designs of the courses, drafting a pedagogical model for using performing arts within higher education (section 5).

\section{Performing arts in higher education}

While it is true that teaching can be considered a performing art (Sarason 1999; Whatman 1997; Bale 2020), the use of performing arts strategies in education has given rise to a fruitful and increasingly sophisticated field of work and reflection. In fact, the use of performing arts has been expanding quickly at primary (Schonmann 2011), secondary (Harland et al. 2000, Motos 2009) and tertiary education levels (García 2004; Jogschies et al. 2018). In addition, many authors have pointed out the relevance of performing arts for child development (Daykin et al. 2008; Goldstein \& Winner 2012; MacDonald et al. 2020) in terms of different psychological and social aspects. Pioneering work in this field has been conducted, and continuous improvements have been made, in the domain of teaching foreign languages (Blanch 1974; Via 1976; Giebert 2014; Stern 1980; Richards \& Rodgers 1986), an approach that continues to this day (Galante \& Thomson 2017; Guttiérez 2004; Mentz \& Fleiner 2019; Piazzola 2018). In parallel, theater, music and improvisation have been used as resources for teaching subjects as diverse as history (Taylor 2008), mathematics (Smith 1998), civic education (Pellegrino et al. 2010), social science (Gravey et al. 2017), archeology (Trimmis \& Kalogirou 2018) or medicine (Hooker \& Dalton 2019). 
However, it is not simple to historicize the educational uses of performing arts because, among other reasons, there is no clear agreement about what art is, and the labels used to describe the strategies deployed in the classroom proliferate without clear definitions. Following Oreck, we can recall some of the classic discussions on this subject:

John Dewey $(1934,1958)$ placed the arts within the realm of experience as opposed to product. For Dewey, the sources of artistic experience were found in everyday life and were a central educational value (Jackson 1998). According to Dewey, the nature of the experience - the process itself, and its aesthetic qualities - identifies an experience as artistic. Vygotsky (1971) agreed, writing, "Art is a method of experiencing the making of a thing, but what is made is of no import in art" (p. 57). For many artists, aestheticians, and art historians, art exists, "not in objects, but in a way of seeing" (Weschler \& Irwin 1982: 186). This broader view of art is also widely applied to teaching. Gage (1978) calls teaching a "practical art... a process that calls for intuition, creativity, improvisation and expressiveness" (p. 15). Dewey believed that the teacher's status as an artist is "measured by his ability to foster the attitude of the artist in those who study with him" (1933: 288). (Oreck 2006: 3).

Moreover, in addition to the different perspectives on the educational uses of the arts - and the performing arts in particular - there are also great variations in the specific activities employed (Redington 1983). Indeed, the strategies used in the classroom differ substantially for different reasons. On the one hand, the artistic disciplines from which strategies are taken are multiple, including theater, dance and music, with different variations and hybridizations for each one. At the same time, the typical techniques in each of these domains have different roots and specific traditions. However, regarding this diversity of definitions and performative resources, we would like to point out that it is possible to recognize a continuum, with two main poles, when considering the function that these adopted strategies have in the educational process.

The performing arts can be used as one additional tool among others. In this case, the general curricular design remains traditional, but with the addition of certain "artistic moments". This is the case, for example, for literature classes in which certain classical plays are dramatized, or for language courses in which songs or roleplays are used in the target language to motivate, entertain, inspire or simply to include a specific aesthetic dimension. At the other end of the spectrum are those strategies that call on the performing arts to structure - or deconstruct - the entire curricular design. Here we are no longer dealing with just another teaching resource among others. In these cases, the use of performing arts much more radical, as it is the core of the activities. In this way, relationships between peers and between teachers and students, as well as the evaluation modalities and content organization, are 
completely transformed. Between both extremes it is possible to recognize a continuum with intermediate proposals.

In Switzerland, the tradition to teach with performing arts is not widespread. A recent paper reports that "although theater or drama are not a school subject at Swiss Elementary Schools, a wide variety as well as a large number of theater projects are on offer" (Sack et al. 2019: 61) - mostly inspired by passionate teachers with a personal taste for performing arts thanks to the "curriculum 21" transdisciplinary projects in the German-speaking schools, and linked to after-school activities in the French-speaking part. The same authors report that "competence centres of theatre education (Theaterpädagogik) exist at five Universities of Education, offering assistance to teachers in the conceptualizing, planning and realizing phases of theatrical projects" (Sack et al. 2019: 65), whose academic staff have received proper training in the field of acting and performing arts. At the University level, the use of performing arts seems to contradict the expectations of standard pedagogy. The authors add that "in the current context informed by the Bologna reform and by general societal trends towards measurable and efficient learning outcomes, the professionals involved in theatre education at the Universities of Education experience difficulties in meeting the challenge of keeping open spaces for the exploration towards (self) discoveries and for the creation of the unconditioned aesthetic experiences" (Sack et al. 2019: 65).

We will now present two teaching settings that try and create such open spaces for exploration, representing two variants within the continuum described above in the context of University teaching in Switzerland. We will then reflect on their similarities and differences in order to highlight key directions and conditions for expanding the use of performing arts in Higher Education.

\section{Teaching engineering through performing arts}

\subsection{Origin of the project and pedagogical goals of the course}

Since obtaining his Ph.D. in Microengineering in 2000, Simon Henein has become a recognized leader in the design of novel mechanisms with sophisticated dynamic properties, dedicated to mechanical watches, surgical instruments and aerospace applications. His related undergraduate and graduate teaching focuses on micromechanical design, with an emphasis on the creative process. In parallel, he developed a strong interest in improvised arts, particularly in instant composition dance ${ }^{1}$. He participated in numerous workshops led by

\footnotetext{
${ }^{1}$ Santos, M. S. C. (2017). Instant composition: choreographic training of the dance artist and his corporeality. Revista Brasileira de Estudos da Presença, 8(1), 167-93
} 
internationally renowned improvisers, developed his own artistic practice and founded a dance company in 2013. His experience in these two creative disciplines allowed him to identify a powerful synergy: improvisation as an efficient technique for developing collective work approaches, reflexivity, situated knowledge and embodied cognition. He successfully exploited this synergy in his role as an engineer directing research projects, while employed as Head of the Micromechanical and Horological Design Laboratory at EPFL (Ecole Polytechnique Fédérale de Lausanne, Switzerland). Based on this experience, he initiated, in 2017, a new course bridging the engineering and humanities faculties at the EPFL, entitled Collective Creation: Improvised Arts and Engineering ${ }^{2}$ (also known as "improgineering"). This elective year-long course is part of EPFL's Social and Human Sciences program.

The Improgineering course examines the creative processes in science, engineering and the performing arts. The pedagogical goals of the course are to develop students' listening and expressive capabilities in order to strengthen their collective creative potential. The approach involves the student learning some of the improvisation techniques used in the performing arts (dance, music, theater) and relating them to the design techniques used in engineering.

The following learning objectives are mentioned in the official course description: comparing the improvisation techniques of various performing arts; explaining the similitudes and differences between these techniques and the practices of engineering; presenting live shows; developing one's scenic presence; and analyzing performances in terms of dramaturgy, space, time and audience interaction.

The first editions of the course led to a video clip $^{3}$ presenting the course (a joint EPFL and Arsenic theater press release ${ }^{4}$ ), and the publication of a collective booklet ${ }^{5}$ presenting the course from the teachers' and students' points of view.

\subsection{Structure of the Improgineering course}

The course is open to all first-year master's degree students. Classes are held once a week throughout the academic year. The number of participants is limited to 25 , in order to be compatible with the size of the studios and to allow the creation of a "tight" group of students. Registration is on a "first come, first served basis" once the online registration portal opens, approximately one month before the semester starts. The course is supported and hosted by

\footnotetext{
2 Improgineering - Collective Creation: Improvised Arts and Engineering. In: https://instantlab.epfl.ch/improgineering/.

${ }^{3}$ https://vimeo.com/281099868.

4 https://instantlab.epfl.ch/wp-content/uploads/2018/10/Improgineering_Communiqu_FR.pdf.

5 https://instantlab.epfl.ch/wp-content/uploads/2018/10/improgineering 180x250 26.04.18 extrait.pdf.
} 
the Centre d'art scénique contemporain (Arsenic theater ${ }^{6}$ ) in Lausanne, a well-known incubator of contemporary performing arts.

Attending the course is voluntary, as with all other courses at EPFL. Regarding attendance rate, on average approximately $80 \%$ of the students present at each class. Participation in the workshops is also voluntary: the students who are present can attend workshops just by watching them, without participating actively, and can retract from the workshops at any time if they wish (in practice such situations have happened only on very rare occasions). Students work in groups formed freely.

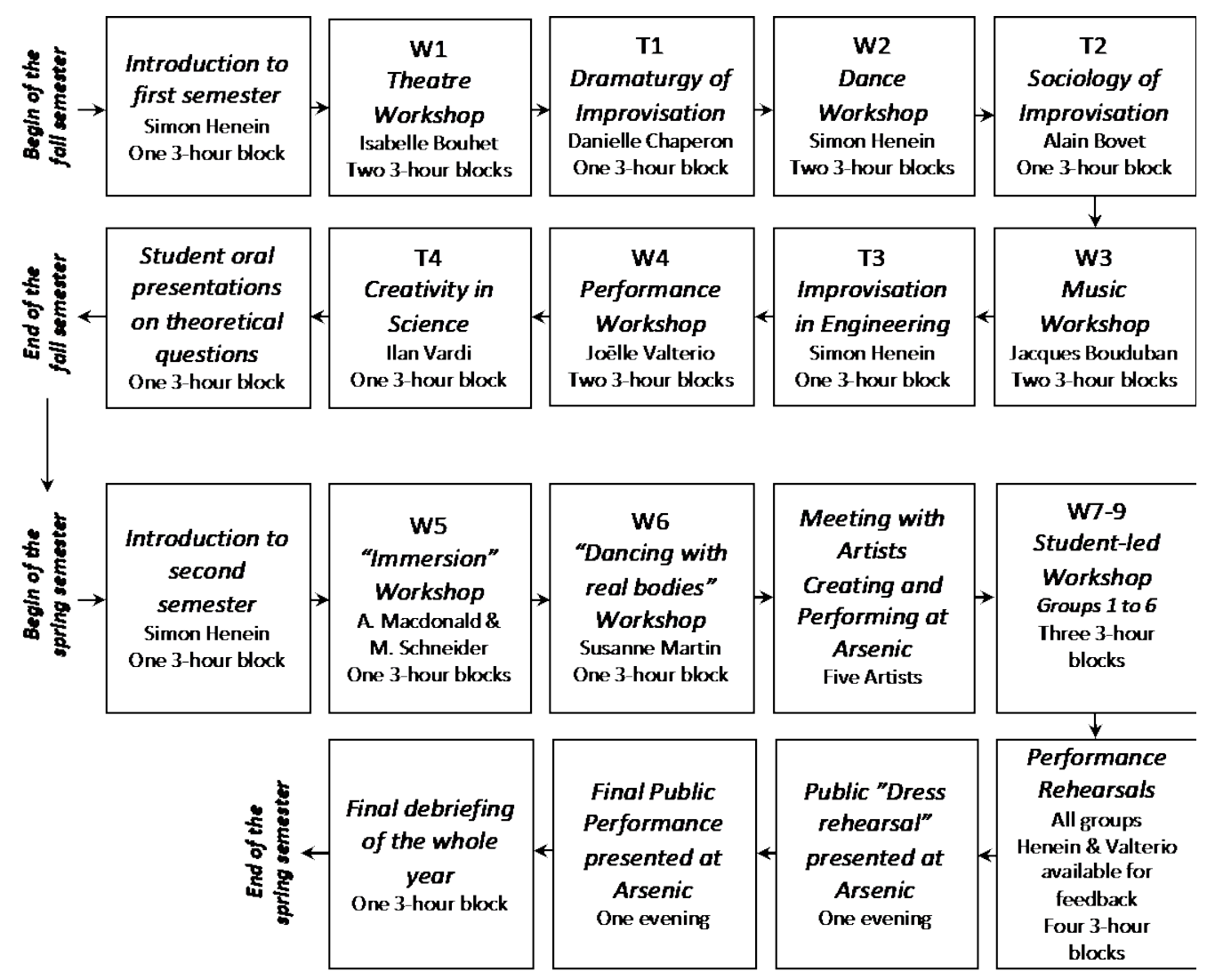

Fig. 1: Structure of the Improgineering course, consisting of twenty-eight 3-hour weekly blocks spread over two 14-week semesters.

\subsubsection{First semester}

During the first semester, the workshops explore improvisation in dance, theater, music and performance art. Additional lectures cover the dramaturgy and sociology of improvisation, improvisation in engineering design, and creativity in science.

The content of the first semester is distributed over fourteen 3-hour weekly blocks, following the structure presented in Figure 1. The teachers are Danielle Chaperon ${ }^{7}$, Alain Bovet $^{8}$, Simon

\footnotetext{
${ }^{6}$ https://arsenic.ch.

7 Professor of Dramaturgy and Director of the Centre for Theater Studies at the University of Lausanne.

${ }^{8}$ Professor of Communication at the University of Applied Sciences and Arts Western Switzerland.
} 
Henein ${ }^{9}$ and Ilan Vardi ${ }^{10}$ for the four theoretical blocks (T1-T4), and Isabelle Bouhet ${ }^{11}$, Simon Henein, Jacques Bouduban ${ }^{12}$ and Joëlle Valterio ${ }^{13}$ for the workshops.

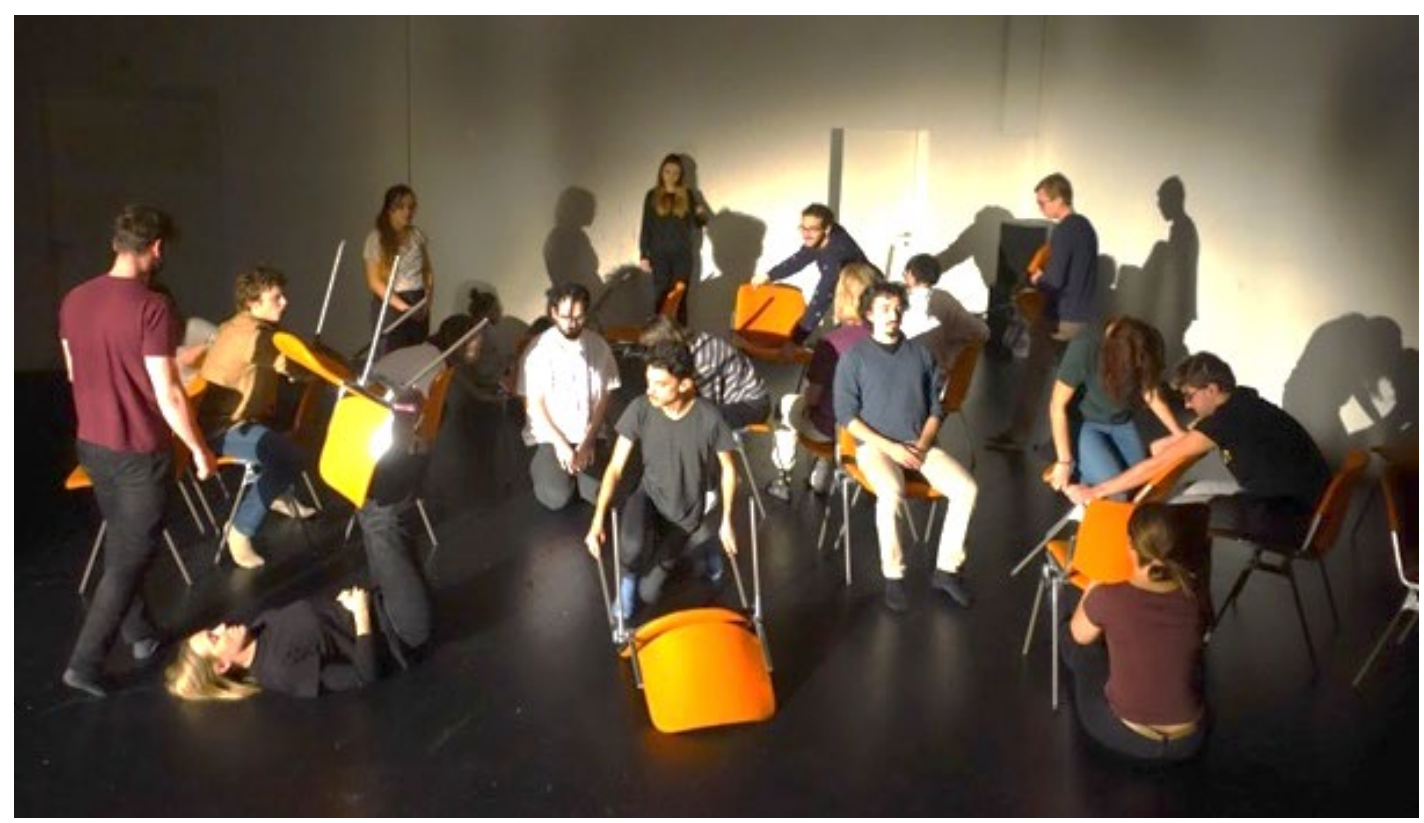

Fig. 2: Photograph taken during the Performance practical workshop (W4) during a collective improvisation moment where chairs were used as artifacts. (Credits: Instant-Lab, EPFL).

\subsubsection{Second semester}

During the second semester, which is also distributed over fourteen 3-hour weekly blocks (see Figure 1), students work in fixed groups of three to five towards an improvised performance based on physical artifacts they have created, with the goal being to explore creativity in engineering and improvisation. The only constraints are the following: the duration of the performance is 12 minutes; all performers are physically present on stage during most of this duration; actions performed on stage are improvised; an artifact designed and realized by the students is present on stage; and the installation and removal of the artifact from the stage lasts less than 2 minutes to allow for the continuous presentation of all performances in a row.

Two 3-hour workshops at the beginning of the semester focus on reactivating the practical learnings of the first semester. The first one, entitled Dancing with Real Bodies, is given by

\footnotetext{
${ }^{9}$ Professor of Microengineering at EPFL, Director of the Micromechanical and Horological Design Laboratory at EPFL, and dancer with Compagnie L'Âme-de-Fonds.

${ }^{10}$ Mathematician and Senior Scientist at the Micromechanical and Horological Design Laboratory, EPFL.

${ }^{11}$ Actor and theater director (Conservatoire Francis Poulenc, Tours, France).

12 Independent cellist, composer and actor.

13 Performance artist (Master's in Contemporary Arts Practice from Bern University of Arts, and Certificate of Advanced Studies in Dramaturgy from University of Lausanne).
} 
Susanne Martin ${ }^{14}$. Based on contact improvisation ${ }^{15}$, it focuses on physical touch as a means for collective action. The second one, entitled Immersion Workshop, is given by Alexandra Macdonald ${ }^{16}$ and Mathieu Schneider ${ }^{17}$. It focuses on the creation of short, instant composition pieces based on improvised movement and improvised music.

Ten 3-hour blocks are dedicated to the creation of students' performance pieces. The blocks include five 1-hour workshops; these are led by each group of students to involve the rest of the class in each ongoing piece creation and to collect feedback. During this whole period, the groups are coached by several performance artists ${ }^{18}$ from the Arsenic theater, as well as other artists who give them creative support. The course culminates with two public performances presented in one of the Arsenic theater studios, with basic theater lighting and an audience of approximately 60 persons. The first public performance is called a "Dress Rehearsal"; the second one is called the "Final Performance" and is evaluated by a jury.

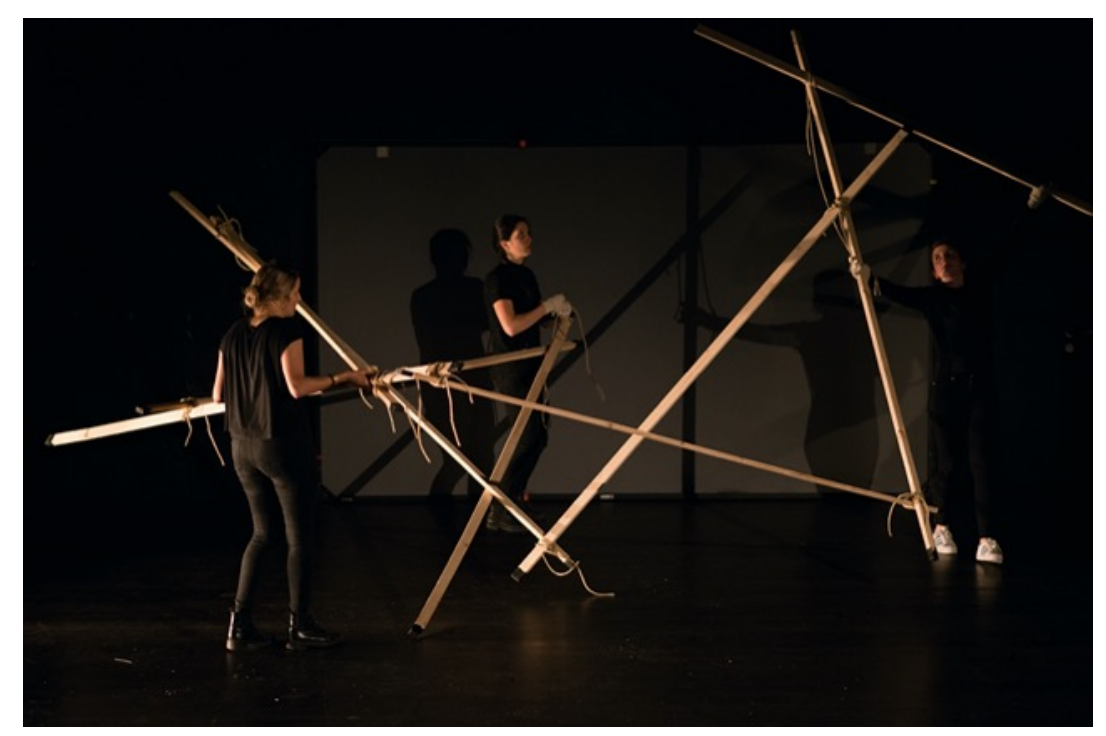

Fig. 3: Photograph taken during the final public performance presented at the Arsenic theater on 23 May 2018: one of the six groups of students is improvising with a wooden articulated artifact. (Credits: Instant-Lab, EPFL).

\footnotetext{
${ }^{14}$ Artist, researcher, and teacher in the field of contemporary dance and performance, who holds a Ph.D in artistic research from Middlesex University, UK.

${ }^{15}$ Contact improvisation is a specific practice and technique within dance improvisation, focusing on touch and weight exchange.

${ }^{16}$ Former dancer of the Cie Alias (Guiherme Botelho) company and yoga teacher.

${ }^{17}$ Flautist and music teacher at Conservatoire de musique neuchâtelois in Neuchâtel (Switzerland) and at the Haute Ecole de Musique (HEMU) in Lausanne (Switzerland).

${ }^{18}$ Including Maud Blandel (dancer), Tiphanie Bovay-Klameth (actor), Audrey Cavelius (actor), Pamina de Coulon (performer), Claire Dessimoz (dancer), Christophe Jaquet (actor), Nicole Seiler (choreographer) and Immanuel de Souza (musician).
} 


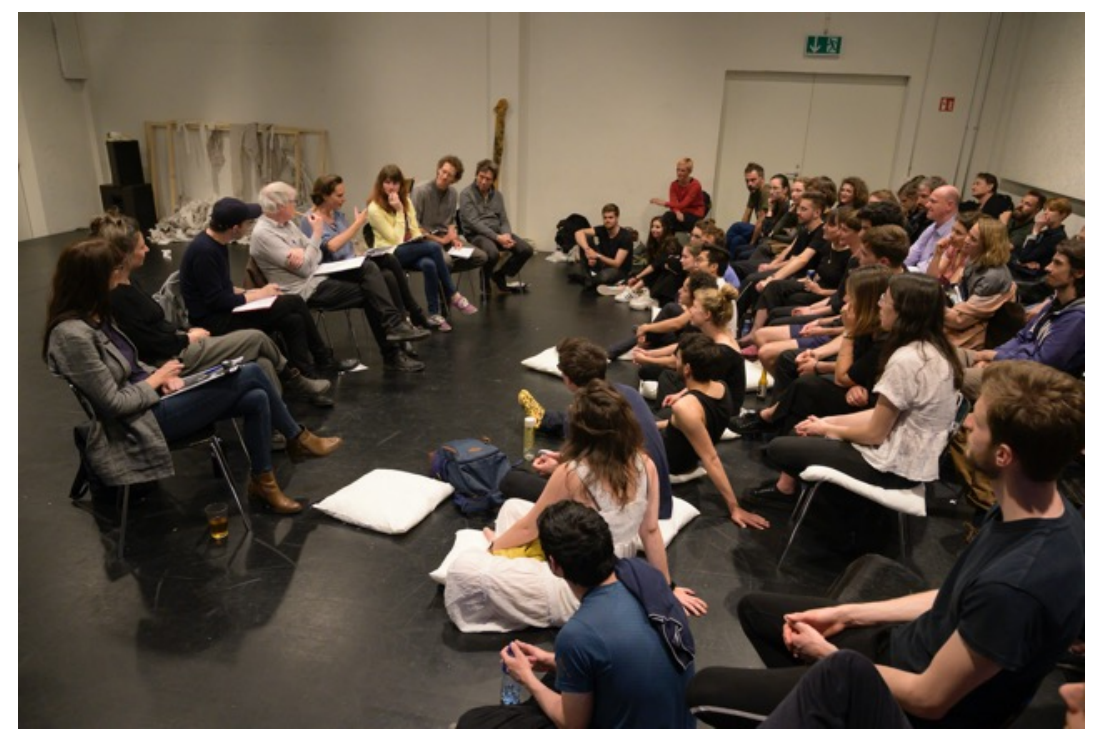

Fig. 4: Photograph taken a few minutes after the final public performance presented at the Arsenic theater on 22 May 2019 , during the discussion between the jury, the students and the public. (Credits: Instant-Lab, EPFL).

\subsection{Evaluation in the Improgineering course}

Course evaluation is based on three deliverables: an individual reflexive diary (assessed in four parts over the full academic year), an oral group presentation answering one of the questions stemming from the theoretical blocks, and a 12-minute, on-stage, public, improvised group performance presented at the end of the year. These deliverables are described in more detail below.

Firstly, the students are asked to write a reflexive diary during the two semesters, equating to approximately one A4 page per week (optional annexes such as drawings, photographs and recordings are welcome). The time dedicated to this work, according to the study plan, is 2.5 hours per week. The diary is described to the students as follows: "The role of the Reflexive Diary is to think about what you experience and learn during the course; as one can think out loud, one can think through writing. The style is free and personal and does not need to be achieved or polished. It is important not to delete text as you write, but always add, even if this sometimes leads to contradictions. It is not a report about what has happened during the class, but a trace of your own learning process and associated reflections." Examples of questions are also proposed, including: "What have I learned?," "Which details within the exercises touched me, interested me, perturbed me, disturbed me, appealed to me most?," "Which resistances did I encounter and which strategies did I use to overcome them?," "How could what I learned be useful for my future profession or for my life in general?," "What do I find beautiful, poetic, fragile, banal, strong, interesting?" and "How did I solicit my body consciousness during the exercises?". Figure 5 is presented to the student in order encourage them to sweep their foci of attention over the various fields of the teaching events. 


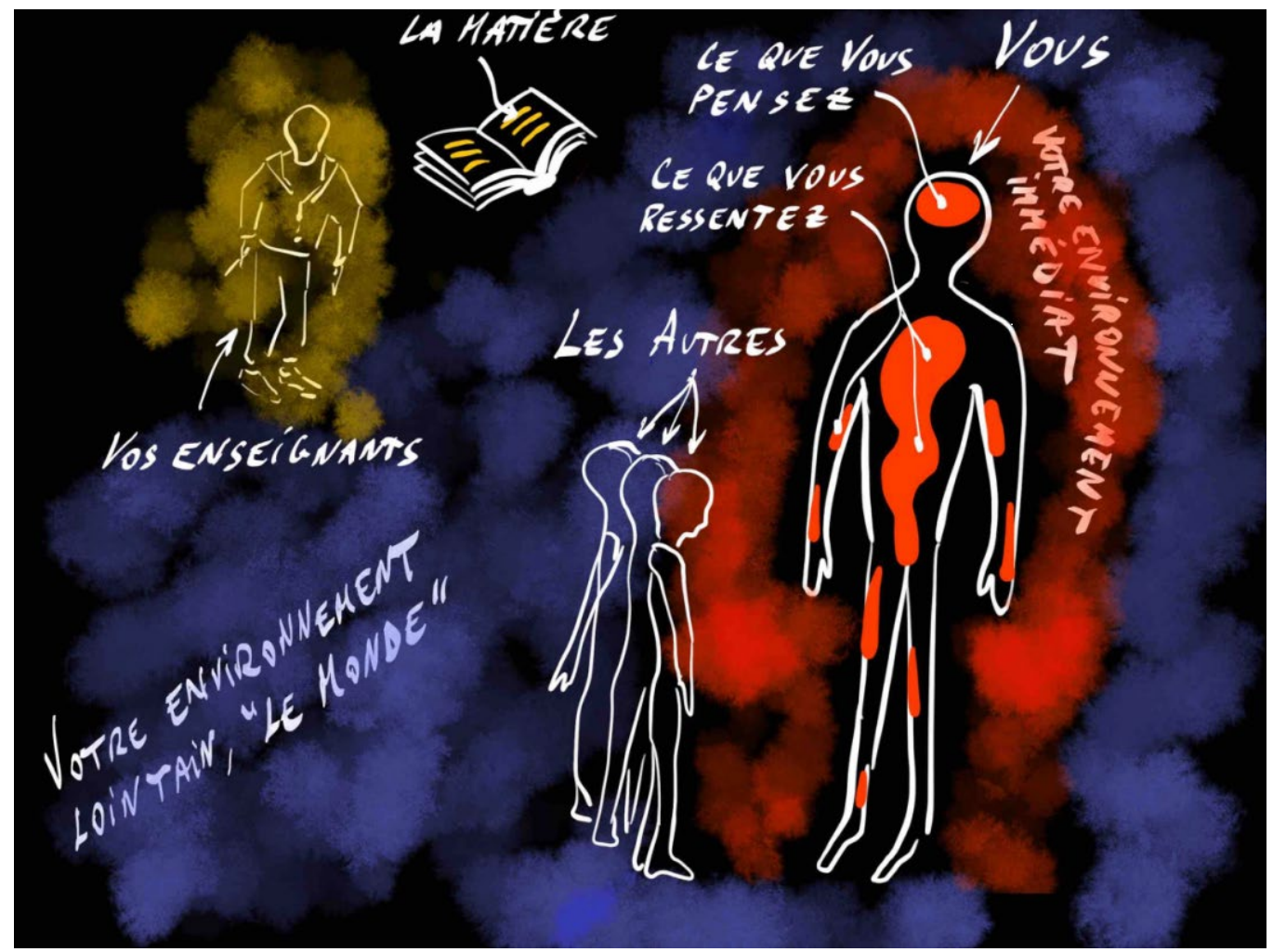

Fig. 5: Illustration of some of the foci which can be used while writing the diaries: "what you think; your immediate environment; the others; the material taught; the teachers; the far-away environment; the world."

The evaluation criteria for the diaries concern the diversity of the foci, the finesse of the observations and analyses, and the progression between the parts of the diaries following teachers' feedback. In the middle of the semester, individual meetings are organized between each student and one of the two main teachers in order to provide feedback about the way they write in their reflexive diaries.

Secondly, at the end of the first semester, the students form groups of three and give a 12minute oral presentation in front of the rest of the class, during which they answer a question formulated by the teachers of the theoretical blocks. The students' oral presentations are based on a question suggested by the teachers in the first semester; for example, "Which function(s) can an artifact have within an improvisation regime as defined in this course?," "How does a collective improvisation differ from an individual improvisation?" or "Can creativity be taught?".

The structure of the presentation consists of contextualization of the question based on: the content of the respective theoretical block; discussion of the question and its relevance in the frame of the Improgineering course; and discussion of the question and its relevance in the frame of the students' studies and future profession. The evaluation criteria for the oral presentations are: the clarity of the contextualization; the richness and pertinence of the external references; the richness and pertinence of the students' own contributions; and the balance of speaking time among the three group members. 
Thirdly, the final performance is evaluated by a jury ( $50 \%$ of the grade) as well as the two main teachers (50\% of the grade) according to the following general criteria: spatial dimension of the performance; rhythmic dimension of the performed actions; sound dimension of the performance; integration of the artifact within the piece; visual or graphical aspects of the performance; and pertinence of the text written to present the piece to the audience prior to the showing.

\section{Teaching psychology of migration through performing arts}

\subsection{Origin of the project and pedagogical goals of the course}

Laure Kloetzer's PhD, obtained in 2008, was in the field of sociocultural psychology; that is, psychology focusing on human development in social contexts, especially on the interplay of micro-, onto- and socio-genesis. Key aspects of studies in sociocultural psychology include human subjectivity, social interactions, cultural mediations, sociomateriality and institutional dynamics. Laure Kloetzer joined the Institute of Psychology and Education (IPE), University of Neuchâtel, in 2015 as Assistant Professor. There she met many colleagues deeply invested in their teaching, who were developing a critical reflection on their own practice, and creating new ideas to improve the teaching and learning process. The institution also offered some space for innovation in pedagogy, thanks to its support of "innovative pedagogical projects".

Within the IPE, Laure Kloetzer and her colleagues experimented with new boundary-crossing learning activities with the students, inspired by the notion of third or transitional spaces. For example, some of the individuals designed a course to teach the basics of the theory and practice of sociomateriality in education. In this course, hands-on activities were organized jointly by teachers and students, including two workshops geared to children (aged 411 years) and their parents, in which the participants were involved in creating musical instruments and inventing figurines' means of transportation (Cattarruzza et al. 2019).

As the University of Neuchâtel was involved in a National Center of Competence research program on the mobility-migration nexus (called NCCR - On the Move), Laure Kloetzer and Gail Womersley engaged in teaching a new course called Psychology of Migration. This course introduces bachelor's degree level students to the psychology of migration from a sociocultural perspective. The course description explains: 
Migrants' mental health is affected by many factors related to pre-migratory experiences as well as conditions for adapting to the host country. The interaction between these factors evolve in time, with moments of relative balance or moments of ruptures and crises. To allow students to understand and appropriate as much as possible the content of the course, we use two main pedagogical resources: on one hand, selected readings, on the other hand, theater games and the collective creation of a short performance, based on fiction books describing the subjective experience of migration.

The idea of using performing arts in teaching came from an initial concern about studying such delicate issues: it should not be purely intellectual, far from political implications and participants' lived realities. The goal of the course is, therefore, to introduce students to the psychology of migration in a way that enables them to connect the scientific theories, models and concepts with their everyday life and human sensitivity. Collective discussions, the construction of a short play and engagement of the students' bodies through theater, prevent them from keeping a purely "Sirius view" on the topic, and force them to engage their thinking with the subjective experience of migration in its sociopolitical context.

Therefore, the pedagogical goals of the course are to learn key concepts and theories regarding the sociocultural psychology of migration. The course covers the topics of integration, family and schooling, as well as mental health and local language acquisition. So far, additional goals like expressing oneself, group work and collective creation have not been explicitly mentioned as pedagogical goals in the course description, although theater here is understood as a pedagogical tool to connect one's scientific learnings with one's personal experience in society. The use of theater colors all experience within the course, as students' work is from the beginning focused on the collective creation of a short play inspired by novels that entrench the person in the experience of migration.

\subsection{Structure of the Psychology of Migration course}

Attending this course is voluntary. The course is limited to 20 students. Students are invited to participate based on their letter stating their motivations and drives for wanting to attend the course. Most of these letters reveal a combination of personal interest for the topic of migration and some desire (not always without fear) to participate in theater productions at the university. The course has been running since the so-called migration crisis of 2015-2016, and most letters are very touching, with students reflecting on their discomfort, and sometimes describing feelings of being lost, overwhelmed or helpless, regarding the mediatic and political treatment of migration. A significant minority of students (around one-third) also describe being personally touched by migration issues, either as first- or second-generation migrants. Hence, some of the topics studied in the course (e.g. the redefinition of family 
relations because of migration, work issues, the challenges of staying in touch with distant relatives, the challenges of expressing oneself in a foreign, borrowed language, or the challenges of living in between two societies and two worlds) echo quite directly their experience. Most students do not have any experience with performing arts, although some have studied music, dance or circus, and sometimes performed in local theaters.

Psychology of Migration is a semester-long course, distributed over fourteen 2-hour weekly blocks consisting of an introduction, a theoretical part, a theatrical part and a conclusion.

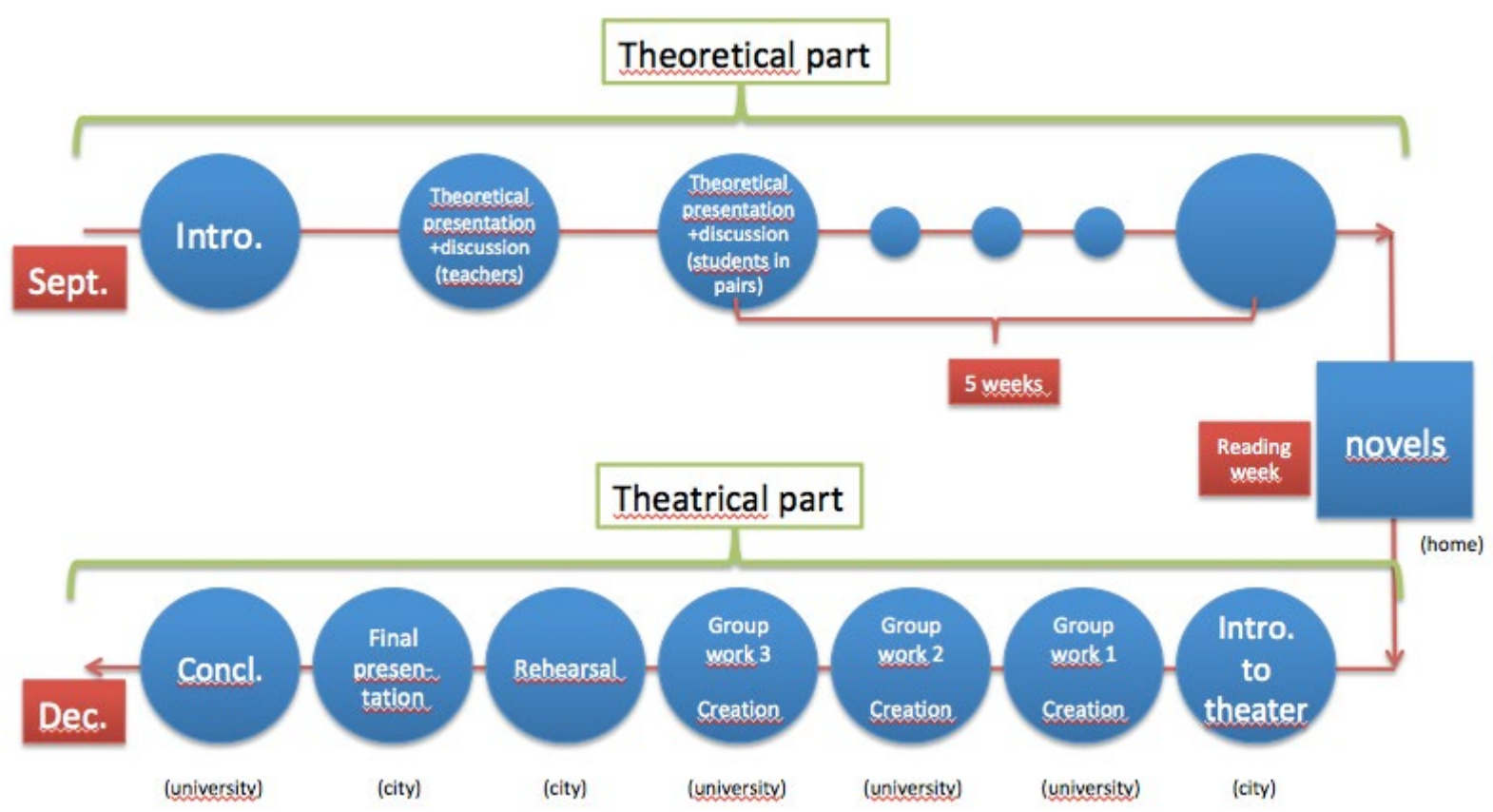

Fig. 6: Structure of the Psychology of Migration course.

\subsubsection{Introducing the course}

The goal of the course, its content and its logic are introduced on the first day. The goal is to study the psychology of migration using scientific papers and the collective creation of a short theater play based on works of fiction. Regarding content, students (a) study, present and discuss scientific papers in a playful mode (theoretical part), and (b) create and collectively perform a short theater play. The logic of the course is introduced as being a space in which knowledge will be co-created.

A similar logic covers the two parts of the course, the so-called "theoretical" and "theatrical" segments. The teachers frame this logic as being a spirit of collective reflection and dialogue, the sharing of ideas and experiences, playful experimentation, openness, and listening. This pedagogical frame is enacted by the two teachers, who also require from the students a formal engagement with an explicit set of rules: (a) listen to others with a spirit of openness and respect; (b) keep all discussions confidential as they may deal with delicate aspects of others' lives; and (c) participate actively in the course, and inform of any absences in advance, as the 
group dynamics are critical. Students know that they are also expected to: (d) engage in diverse collective activities, particularly in the collective creation of a 5-10 minute play based on a fictional story; and (e) write a learning diary, which will be the main basis for the final assessment. The teachers make the formal expectations for the course very clear: "each student will have to do theater with a group, read and discuss two scientific papers per week, participate in discussions, prepare and present one scientific paper with a peer, and write individually a learning diary". They also insist that students, at this point, are free to leave or stay, but if they decide to stay, they should participate in all course sessions and agree to the rules stated above.

The two teachers then actively construct a sense of collective work and reflection. They open the second part with a roundtable discussion, to enable all students to introduce themselves and describe what attracted them to the course. This roundtable setup has, in previous years, been a very intense experience; students have been surprised by the deepness and honesty of their peers' words, and by the fact that many of them share in this space parts of their personal and family story which they have never been able to talk about in the academic setting. This roundtable discussion demonstrates to the students the diversity and richness of (direct or indirect) migration experiences, and highlights that they are not alone in feeling some discomfort with these issues in their social life.

The latter half of the Psychology of Migration course also introduces key theoretical models by which to understand the dynamics of migration, the subjective experience of migration and issues related to mental health. At the end of the second half, the scientific papers - discussed in the theoretical phase of the course - are introduced. Groups of two are then formed based on students' expressed interest for some texts or topics. Finally, the fiction books for the theatrical part are introduced. The teachers select four to five different novels using the following criteria: the novels should talk about migration; they should describe a first-person experience of migration; and, being an artistic work, they should offer a fully elaborated reflection. We also tell the students that they can themselves suggest books, movies or songs that will be shared with the class after review by the teachers. The final selection of art works for 2018-2019 is shown in Figure 7. 


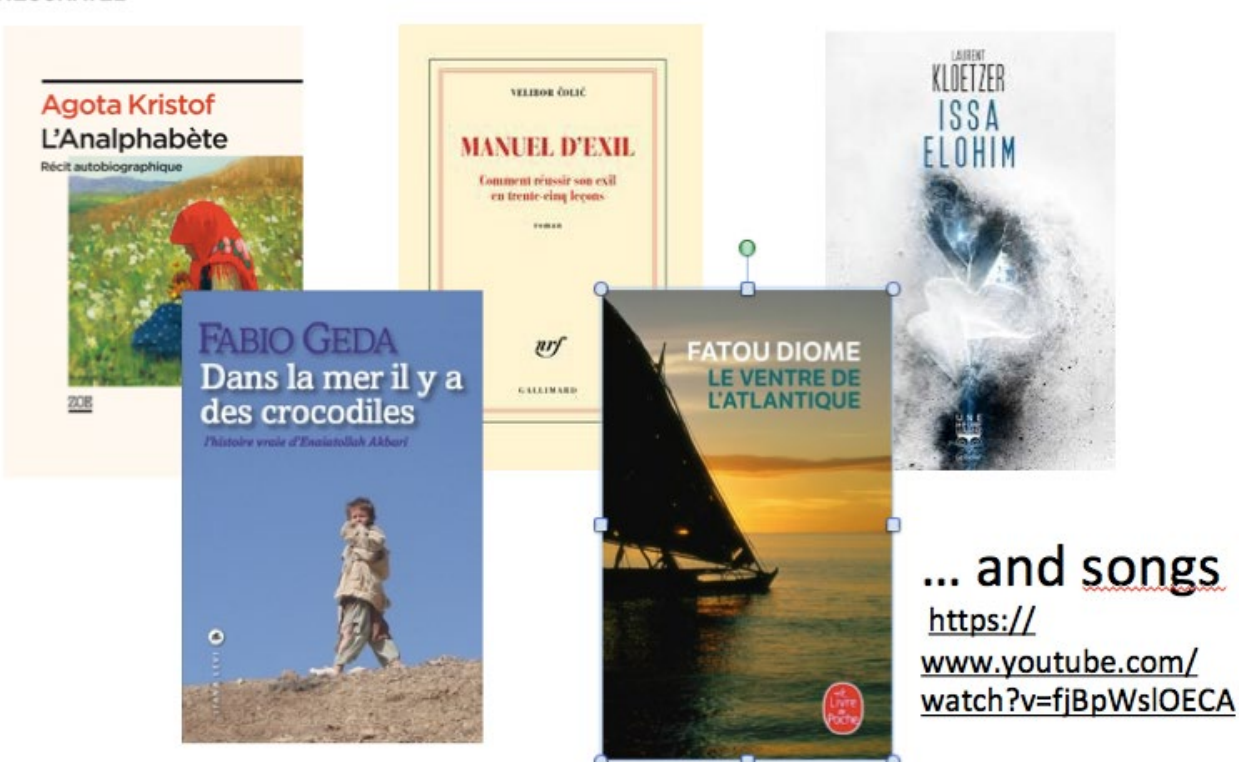

Fig. 7: Selected art works for the theatrical part of the Psychology of Migration course.

In their learning diaries, the students' writings about the two course parts show that they clearly experience a desire to promote dialogue and collectively create knowledge within the course. One student writes, for example:

First course part. What to say... I have already been able to travel in the thoughts and wishes of each of the participants. I was touched that this kind of topic gets such a special place at the university. I could see that each one had, in their own way, a deep interest for migration questions. I appreciated how sincere my colleagues were: "I am here because, on migration, I don't know anything" ... This course involved real questioning for me, a way to confront to myself, leave my small comfort zone. ... I already know that my sensitivity will be at the foreground. I liked the approach that the teachers suggested within this first course part a lot: sharing, transmitting, wishing to enrich the other, but, first of all, to listen to her share her experience.

\subsubsection{Theoretical segment}

For the five next course sessions, the structure is the same: two groups of pairs present a scientific paper that everyone has read and prepared for, with instructions to present a key concept of the paper in detail, and to then create an activity that will engage the group in a critical and creative reflection on this concept. What this activity should be is not explained, but it can be anything that helps the group engage with the chosen concept and topic of the day. Students usually design playful activities, like riddles, roleplaying games or short performances. The discussion opens after each presentation, and, in this space, many personal thoughts on the relevance or limits of the theory for understanding their personal experience can be expressed. Each course session is dedicated to a specific topic, so that the two texts and pairs of presenters are not disconnected, and the group discussion usually 
increases in deepness and richness after the second presentation. We study five different topics related to three different approaches: the macrosocial context, sociocultural aspects and the clinical dimension of the psychology of migration. In the last year, we have studied the following topics: family, culture and education, education, language acquisition, and mental health.

This part of the course ends with a reading week at the University of Neuchâtel; this is a oneweek break in which students are encouraged to read and revise their course-related work. During this week, the students are instructed to read the chapters (selected by the teachers) of the selected novels, and, if they like some of them, to read the books and select two books that they would like to work on for the creation of their theater play.

\subsubsection{Theatrical segment}

After the reading week, the theatrical part of the course begins. We meet at the "Lockart," an association in the city center offering a dance studio. The students meet the third teacher of the team, who is a drama teacher, stage director, actor and owner of a theater company. We have been working with two drama teachers, Julie Burnier (Compagnie Pied de Biche) ${ }^{19}$ and Sophie Pasquet Racine (Compagnie Les Freckles) ${ }^{20}$, who bring different energies and techniques to the course. Students and teachers, bare feet in the dance studio, participate in theater games and short improvisations. At the end of this course segment, groups are formed based on the students' choices of texts (ideally, we form four groups of five students). Then, the groups self-organize to work within and outside the course to adapt these dense artworks, in order to create a short (5-10 minute) and partly improvised theater play.

\footnotetext{
${ }^{19}$ Compagnie Pied de Biche, http://pied-de-biche.ch/

${ }^{20}$ Compagne Les Freckles, https://www.lesfreckles.net/
} 


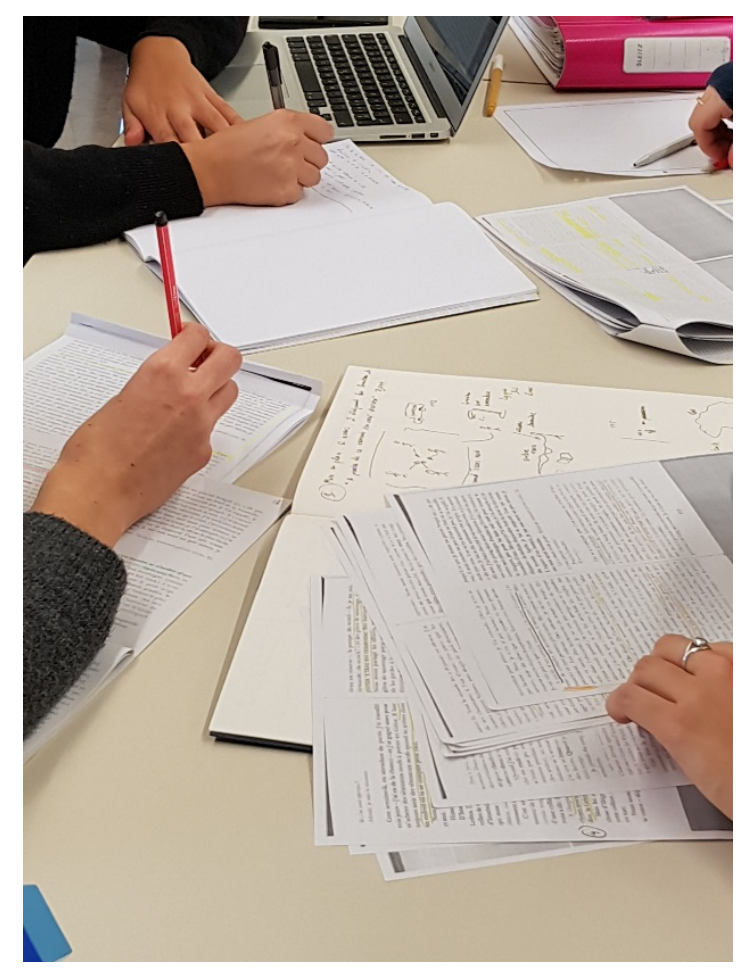

Fig. 8: Collective creation work: creation at the table.

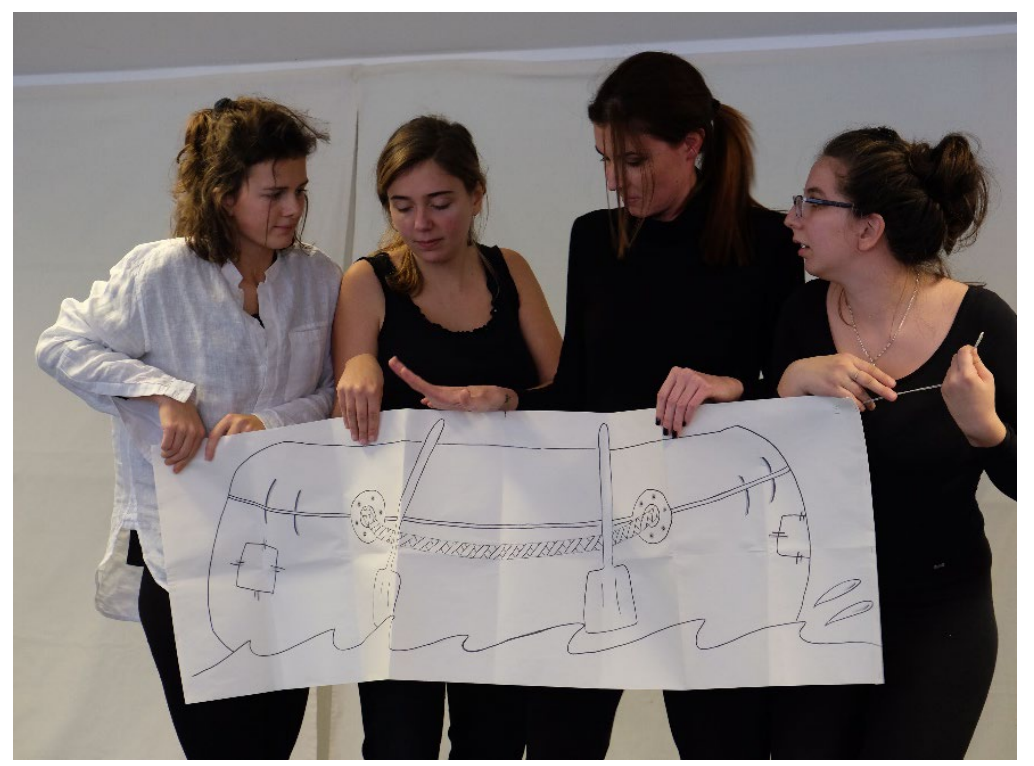

Fig. 9: Collective creation work: creation on stage.

The teachers instruct the students to share why they like the book, and what touches them in it, and they encourage the students not to close this explorative and sharing process too quickly. The groups decide by themselves what they want to do and show. They receive informal feedback from the three teachers, who loosely follow the creation process. Creation happens both at the table and "on stage" within the university and at the Lockart. For the rehearsal, each group presents its work "behind closed doors", with just the three teachers, to keep the final performance a surprise. 
For the final performance, the groups perform in front of all other students, the teachers, and some external guests invited either by the students or the teachers. Each performance is followed by a discussion in which audience members share on what they have seen, felt or thought during the play. After the performance, all students, teachers and guests meet at the neighboring café.

During the final course segment, back at the university, the students re-discuss in small groups how the two parts of the course relate to each other, by mapping and drawing on posters (one per group) the key concepts dealt with in the theoretical presentations and in their theater play. These posters are shared and discussed by the students. Then, in a closing roundtable discussion, the students give their final feedback on the course, and describe what they discovered, experienced, enjoyed, disliked or learned during the semester.

\subsection{Evaluation in the Psychology \& Migration course}

According to the course description, there are some conditions for taking the final assessment: presence and active participation in the course, including reading of the texts and preparing for the discussions; presenting a scientific paper in the classroom; participating in the creation and performance of a theater play; and writing a learning diary, "which will come back to the works done during the course, in a critical and reflexive perspective". The assessment is carried out by the teachers based on the individual learning diaries. This procedure seems to be valued by the students themselves as a coherent strategy within the general pedagogical proposal:

\section{It is true that I cannot imagine another assessment format more appropriate to the goals of the course... (Extract from student's diary referring to the assessment of the Psychology of Migration course related work.)}

The instructions for the learning diary are very open: students should start writing from the beginning of the course, weekly; they should not delete what they have written before, but add a new entry to their diary. The students are free to write what and how they like regarding the content and the form of the diary text. Interestingly, the diaries adopt multiple forms, such as electronic reports and handwritten notebooks, and frequently include non-textual and multimodal material like maps, drawings, pictures, cut-outs, music, puppets, and even a small Japanese-style wooden theater. 


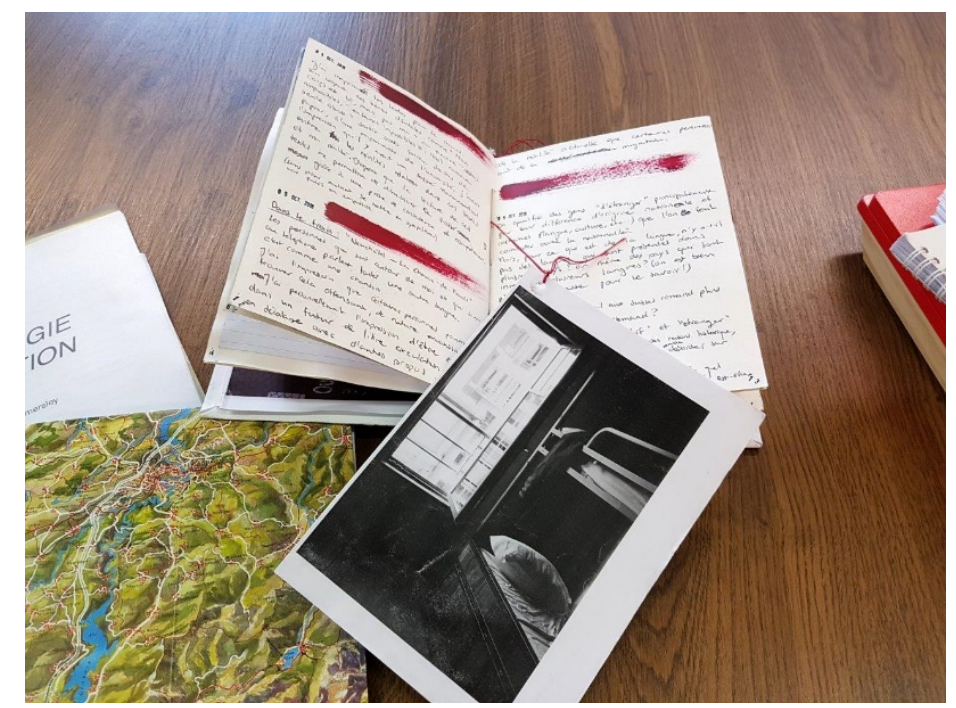

Fig. 10: Some of the learning diaries.

\section{Impressions of the two courses}

In 2016, Simon Henein and Laure Kloetzer met and discussed their impressions of the two courses. These impressions were extremely positive. As well as being enjoyable to teach for both teachers, the courses were apparently extremely appreciated by the students (with 90$100 \%$ of the participants saying that the course was good or very good in the final quality evaluation of the courses). Although the topic, the public, the goals and the methods are different, the students' comments in the quality assessment questionnaires at the two institutions were very similar. Examples of the students' comments are shown in Table 1 below.

\begin{tabular}{|l|l|l|}
\hline Main topics & $\begin{array}{l}\text { Students' comments regarding } \\
\text { Improgineering course }\end{array}$ & $\begin{array}{l}\text { Students' comments regarding } \\
\text { Psychology \& Migration course }\end{array}$ \\
\hline Learning & $\begin{array}{l}\text { "This course is excellent, we learn a } \\
\text { lot" } \\
\text { "Very interesting course. We Wh course is innovating and dynamic. } \\
\text { discover listening to yourself, to the } \\
\text { others, mutual help, collaboration, } \\
\text { creativity, self-tolerance, openness, } \\
\text { presence on stage..." }\end{array}$ & $\begin{array}{l}\text { While we learn theory, other types of } \\
\text { skills get developed, which support } \\
\text { engagement into the topic. What theater } \\
\text { brings is very rich, to understand a topic } \\
\text { which implies much more than theory. } \\
\text { This course makes us want to dig into the } \\
\text { topic and this is one of the key points in a } \\
\text { course I believe." }\end{array}$ \\
\hline $\begin{array}{l}\text { Enjoyment } \\
\text { courses that are } \\
\text { different } \\
\text { nature }\end{array}$ & $\begin{array}{l}\text { "Best course this semester" } \\
\text { "This course is the light during the } \\
\text { week" }\end{array}$ & $\begin{array}{l}\text { "I had a real crush for this course" } \\
\text { "I like it a lot to attend to a course which } \\
\text { is different from the others, which makes } \\
\text { us understand the topic differently" } \\
\text { "What a pleasure to explore learning } \\
\text { forms which are so diverse (diary, oral } \\
\text { presentations, discussions, literature, } \\
\text { performance...) wouaw!" }\end{array}$ \\
\hline
\end{tabular}




\begin{tabular}{|c|c|c|}
\hline $\begin{array}{l}\text { Personal \& } \\
\text { collective } \\
\text { transformation }\end{array}$ & $\begin{array}{l}\text { "This course really allows the } \\
\text { student to resize oneself. It is a } \\
\text { space of openness and reflection, } \\
\text { really active, which drives us in the } \\
\text { best way to change from the } \\
\text { everyday life and traditional } \\
\text { standards of thinking" } \\
\text { "Seriously, this course made me } \\
\text { relive in architecture!" }\end{array}$ & $\begin{array}{l}\text { "Best course in my bachelor's degree: my } \\
\text { expectations were met and above. } \\
\text { Dialogue, emotions, creativity, reflection, } \\
\text { personal research, and management of } \\
\text { group relations, while studying such a } \\
\text { delicate topic as migration. A means to } \\
\text { understand the world in a more creative } \\
\text { way, and more efficient too, and also to } \\
\text { shift the perspective from mine to ours. } \\
\text { Enriching experience, which stays in } \\
\text { memory" }\end{array}$ \\
\hline
\end{tabular}

Tab. 1: Some students' comments regarding the quality of the two courses.

Following these convergent impressions on learning, enjoyment and personal transformation, we decided to launch a research project to understand more about the teaching and learning dynamics involved in the two courses. The ASCOPET project (which stands for Les arts de la scène comme outil pédagogique dans l'enseignement tertiaire, and translates to English as The Performing Arts as a Pedagogical Tool in Higher Education) is a collaboration established in September 2018 between Instant-Lab and the IPE at the University of Neuchâtel (UNINE). This project describes, analyses and evaluates the utilization of performing arts in higher education via a comparative study of two pilot courses. Special attention is given to the embodiment of learning practices in sociomaterial and historical environments, and to human creativity, learning and development in "boundary zones" (Konkola et al. 2007) or "potential spaces" (Winnicott 1971).

Our data documented a change in the course students' perspectives and feelings. The students started the courses with mixed feelings of curiosity, uncertainty, excitement and fear. Their comments highlight the importance of freedom, playfulness and sharing within the course:

I felt a bit childish, free to express myself without conditioning, free to communicate, free to play with others and also with myself. It is difficult to materialize and put into words what I experienced, but when I came home in the evening and called my parents I said: "Listen, I had an unforgettable experience that everyone should be able to have! (...). (Extract from student's diary, referring to the Improgineering course.)

Reading the diaries, we noted evidence of more fundamental transformations: the transformation of the students' views regarding some aspects that we directly or indirectly dealt with in the course. For example, body, consciousness, relations with others, connections between their courses and their life outside the university, or the course topics themselves. There were also changes in the students' relationship to their own body: 
It's incredible how difficult it is to concentrate, but at the same time you discover a new feeling when you do it. It's crazy how I'm almost never in control of my actions: everything is such a trivial automatism. It's also interesting how I gain a lot of confidence when I become conscious of the moment and my movements. (Extract from student's diary, referring to the Improgineering course.)

Eventually, this course has been a nice experience for me. I would never have imagined, in my life, swimming in toilet paper in an improvised performance! What I learnt in this course, is a way to free myself, to improve my self-expression, to be less shy in front of the others. Having an environment in which nothing is wrong, all is fine, nobody judges, allowed me to experiment, to express myself, especially with my body. (Extract from student's diary, referring to the Improgineering course.)

The students stated that they connected the topics of the course to their everyday life. In the Psychology of Migration course, some students, who at the beginning of the course seemed powerless regarding the migration phenomenon, now engage themselves in different voluntary activities:

Thanks to this course, I became aware that the topic of migration is part of my everyday life. (Extract from student's diary, referring to the Psychology of Migration course.)

Similarly, in the Improgineering course, improvisation becomes a part of everyday life, a way of looking at things, people and events with a creative and inclusive perspective, which brings the students happiness and a feeling of connection to others.

We could argue that, at least for some students, the course supports a more radical transformation relating to the "ethos" of the student. Both courses lead to transformations in terms of how the students inhabit the university, their "doing/being" with regard to knowledge, their collective work, their feelings regarding migration and their improvisation. In this sense, the courses enable a change of position, not only at the reflective level, but also at the level of practices, of established forms of travelling through different social institutions. Boundary-crossing and bridging functions are established with one's past and future experience, as well as with other practices and experiences. In this sense, there is some evidence for the transfer of this change of position to other spheres of daily action. Transformation is not just a cognitive change; it is a transformation of the participants' subjectivity that goes far beyond students' understanding of the course topics. 


\section{Conclusion: a pedagogical model to relive higher education?}

Although the Improgineering and Psychology of Migration courses had different designs, public audiences, learning goals, learning activities and academic fields of reference, as teachers we recognized strong similarities between our experiences. The subsequent ASCOPET project scientifically explores the learning dynamics linked to the use of performing arts in these two courses. Our first findings allow us to extract from our experience in these two courses nine main points, enabling us to draft pedagogical guidelines (among others) for the use of performing arts in higher education, which will hopefully be valuable for other disciplines and situations.

\section{Performing arts take place within a global pedagogical design.}

Performing arts are powerful tools when used in combination with a global pedagogical strategy. The necessary changes in teaching include: co-teaching, sensitivity to building collective dynamics, change of teaching place, openness of instructions during the course and evaluations, and changes in the assessment modalities.

\section{Performing arts are the leading activity of the course.}

When considering the continuum mentioned in section 1 on the place of performing arts in curriculum design, performance is a central aspect of both courses. The main goal of the courses is the collective creation of a scenic performance that includes improvisation. This collective creation and performance enhances students' engagement in the courses.

\section{The balance of theory and experience is crucial for learning.}

Theory frames the creative practice and feeds students' reflection process.

4. The combination of performative experience (also bodily experience) in the classroom and its reflection within the diaries is crucial for learning and (self) exploration.

Continuous writing of the diaries engages the students in a reflective activity. Multimodal, open diaries are powerful tools for thinking, and for resignification of the experience, including bodily experience. We have shown (Ramiro et al., submitted) how the diary entries evolve and reshape the bodily experience. 


\section{Freedom and collaboration are essential in the learning process.}

Multiple forms of group work are organized within the courses. Most activities involve a dimension of freedom: although the task is set by the teachers, there is freedom in how it can be answered, and in the negotiations between student groups. The freedom experienced in the content of the course echoes the freedom in the content of the diaries, whose writing is required for the final assessment of the course.

\section{The production of a culturally significant creation is an essential part of the} learning process.

The students have the collective responsibility of producing a performance or play for a public presentation. Therefore, they address their work not only to the teachers but to their peers, and they are accountable to this external audience. This variation of address is one aspect of development (Kloetzer, Clot \& Quillerou-Grivot, 2015). The dialectics of externalization and internalization are another aspect of development. Following the well-known proposal that culture supports and shapes mind development (Vygotsky, 1980; Cole, 2015), mind also develops when it becomes (collectively) cultured.

7. Expansion of space (crossing boundaries between home and university, and theater and university) supports the learning dynamics of the course.

In particular, physical boundary crossings between institutions (university and theater) allows for the hybridization of learning and teaching cultures within academic and artistic practices.

8. Changes of the evaluation modes are required, to ensure consistency between the teaching/learning process and the evaluation process.

"Consistency" here refers to that between the openness of the teaching and learning process (do what you want) and the openness of the evaluation (write what you want). Changes in the evaluation mode include the combined use of a group production and corresponding learning diaries. In addition, there is "open" evaluation; no specific content is expected, rather a special kind of engagement and quality of reflection and contribution.

\section{The teachers play a different, changing role.}

The teachers reject the vertical transmission of a given set of knowledge, and instead engage in building the conditions for collective work and reflection, and the coproduction of experience and knowledge. Co-teaching introduces multiple reference 
points and points of views. Instructions are open and encourage freedom. The course is built with a critical collective dimension between peers, and not with a "star design" in which individual students are mostly connected to the teachers.

\section{The construction of institutional conditions for the collaboration between academic staff and professionals from the field of performing arts should be encouraged.}

These pedagogical settings require the participation of professionals from the field of performing arts (in our cases, dance improvisation, theater and music improvisation) in academic teaching, as well as the use of spaces dedicated to performative workshops and events. This requires a tight collaboration with theaters or dance studios, for example, as well as the possibility to recruit and pay non-academic staff.

These ten dimensions/conditions are not independent. Altogether, they show that the use of performing arts in higher education has the potential to transform not only the relationships of the students to themselves, to others and to the topic under study, but also those of teachers to students, and of artistic and academic institutions; it can also transform our views on the place of the body, collaboration, collective creation and personal exploration in education.

\section{Bibliography}

Bale, Richard (2020): Teaching with Confidence in Higher Education: Applying Strategies from the Performing Arts. London: Routledge, https://doi.org/10.4324/9780429201929

Blanch, Emma (1974): Dramatics in the Foreign-language Classroom. New York: MLA/ERIC Clearinghouse on Languages and Linguistics

Bruner, Jerome (2015): Car la culture donne forme à l'esprit: de la révolution cognitive à la psychologie culturelle. Paris: Retz

Cattaruzza, Elisa; Ligorio, Beatrice \& lannaccone, Antonio (2019): Sociomateriality as a partner in the polyphony of students positioning. In: Learning, Culture and Social Interaction 22, 100332, https://doi.org/10.1016/j.Icsi.2019.100332

Daykin, Norma; Orme, Judy; Evans, David; Salmon, Debra; McEachran, Malcolm \& Brain, Sarah (2008): The impact of participation in performing arts on adolescent health and behaviour: A systematic review of the literature. In: Journal of Health Psychology 13/2, 251-264, https://doi.org/10.1177/1359105307086699

Dewey, John (1933): How we think. Boston: Heath \& Co.

Dewey, John (1934): Arts as Experience. New York: Minton, Balch \& Co. 
Kloetzer, Henein, Tau, Martin, Valterio: Teaching Through Performing Arts in HE

Dewey, John (1958): Experience and Nature. New York: Dover Publications, https://doi.org/10.1038/1811367a0

Gage, Nathaniel Lees (1978): The Scientific Basis of the Art of Teaching. New York: Teachers College Press

Galante, Angelica \& Thomson, Ron (2017): The effectiveness of drama as an instructional approach for the development of second language oral fluency, comprehensibility, and accentedness. In: Tesol Quarterly 51/1, 115-142, https://doi.org/10.1002/tesq.290

García, A. (2004): Comunicación y expresión oral y escrita: la dramatización como recurso. Barcelona: Raó

Giebert, Stefanie (2014): Drama and theatre in teaching foreign languages for professional purposes. In: Recherche et pratiques pédagogiques en langues de spécialité. Cahiers de l'Apliut 33/1, 138150, https://doi.org/10.4000/apliut.4215

Goldstein, Thalia \& Winner, Ellen (2012). Enhancing empathy and theory of mind. In: Journal of Cognition and Development 13/1, 19-37, https://doi.org/10.1080/15248372.2011.573514

Gravey, Viviane; Lorenzoni, Irene; Seyfang, Gill \& Hargreaves, Tom (2017): Theoretical Theatre: harnessing the power of comedy to teach social science theory. In: Journal of Contemporary European Research 13/3, 1319-1336

Gutiérrez, Manuel Pérez (2004). La dramatización como recurso clave en el proceso de enseñanza y adquisición de las lenguas. In: Revista Electrónica Internacional Glosas Didácticas 12, 70-80

Harland, John; Kinder, Kai; Lord, Pippa; Stott, Allison; Schagen, Ian; Haynes, Jo; Cusworth, Linda; White, Richard \& Paola, Riana (2000): Arts Education in Secondary Schools: Effects and Effectiveness. Slough: NFER, 566

Hooker, Claire \& Dalton, James (2019): The performing arts in medicine and medical education. Routledge Handbook of the Medical Humanities, https://doi.org/10.4324/9781351241779-20

Jackson, Philip Wesley (1998): John Dewey and the Lessons of Art. New Haven: Yale University Press Jogschies, Bärbel; Schewe, Manfred \& Stöver-Blahak, Anke (2018): Recommendations for Promoting a Performative Teaching, Learning and Research Culture in Higher Education. In: Scenario 2, 52-56

Kloetzer, Laure; Clot, Yves \& Quillerou-Grivot, Edwige (2015): Stimulating dialogue at work: The activity clinic approach to learning and development. In: Filliettaz, Laurent \& Billett, Stefan (eds): Francophone perspectives of learning through work. Basel: Springer International, 49-70, https://doi.org/10.1007/978-3-319-18669-6 3

Konkola, Riitta; Tuomi-Gröhn Terttu; Lambert, Pirjo \& Ludvigsen, Sten (2007): Promoting learning and transfer between school and workplace. In: Journal of Education and Work 20/3, 211-228, DOI: 10.1080/13639080701464483. https://doi.org/10.1080/13639080701464483

McDonald, Brennan; Goldstein, Thalia \& Kanske, Philipp (2020): Could Acting Training Improve Social Cognition and Emotional Control? In: Frontiers in Human Neuroscience 14, 348, https://doi.org/10.3389/fnhum.2020.00348 
Mentz, Olivier \& Fleiner, Micha (2019): The Arts in Language Teaching: International Perspectives: Performative - Aesthetic - Transversal. Münster: LIT Verlag

Motos, Tomás (2009): El teatro en la educación secundaria. In: Revista Virtual: Creatividad y Sociedad 14, 1-35

Oreck, Barry (2006). Artistic choices: A study of teachers who use the arts in the classroom. In: International Journal of Education \& the Arts 7/9, 1-27

Pellegrino, Anthony; Lee, Christopher Dean; Luongo III, Benjamin; \& Zakaria, Osama (2010): Music as a tool for 21st-century civic education. In: Action in Teacher Education 32/4, 83-95, https://doi.org/10.1080/01626620.2010.549739

Redington, Christine (1983): Can Theatre Teach? An Historical and Evaluative Analysis of Theatre in Education. Oxford: Pergamon Press

Richards, Jack \& Rodgers, Theodore (1986): Approaches and Methods in Language Teaching. Cambridge: Cambridge University Press

Sarason, Seymour (1999): Teaching as a Performing Art. New York: Teachers College Press Schonmann, Shifra (2011): Key Concepts in Theatre/Drama Education. New York: Springer Science \& Business Media, https://doi.org/10.1007/978-94-6091-332-7

Smith, Susan Sperry (1998): Early childhood mathematics. Paper presented at the Forum on Early Childhood Science, Mathematics, and Technology Education (Washington, DC, Feb 6-8, 1998)

Stern, Susan (1980): Drama in second language learning from a psycholinguistic perspective. In: Language Learning 30/1, 77-100, https://doi.org/10.1111/j.1467-1770.1980.tb00152.x

Taylor, Julie Anne (2008): From the stage to the classroom: The performing arts and social studies. In: The History Teacher 41/2, 235-248

Trimmis, Konstantinos Prokopios \& Kalogirou, Konstantina (2018): Performative Archaeology: Exploring the use of Drama in Archaeology Teaching and Practice. In: Scenario 2, 30-45

Via, Richard (1976): Participatory English: Drama. In: Language Arts 53/2, 175-178

Vygotsky, Lev Semionovitch (1971): The Psychology of Art. Cambridge: MIT Press

Vygotsky, Lev Semionovitch (1980): Mind in society. The development of higher psychological processes. Boston: Harvard University Press, https://doi.org/10.2307/j.ctvjf9vz4

Weschler, Lawrence \& Irwin, Robert (1982): Seeing is Forgetting the Name of the Thing One Sees: A Life of Contemporary Artist Robert Irwin. Berkeley: University of California Press

Whatman, Jennifer (1997): Teaching is performing: an alternative model of teacher education. In: Research in Drama Education 2/2,173-184, https://doi.org/10.1080/1356978970020203

Winnicott, Donald (1971): Transitional objects and transitional phenomena. Playing and Reality. New York: Basic Books, 1-25 